\title{
PRODUTIVIDADE E TEOR DE NUTRIENTES EM POPULAÇÕES DE MILHO SAFRINHA SOLTEIRO E CONSORCIADO COM BRAQUIÁRIA
}

\author{
PRISCILA AKEMI MAKINOํ, GESSÍ CECCON² e RICARDO FACHINELLI ${ }^{1}$ \\ ${ }^{1}$ Universidade Federal da Grande Dourados,Dourados, MS, Brasil-priscila_akemi17@hotmail.com,rfachinelli@hotmail.com \\ ${ }^{2}$ Embrapa Agropecuária Oeste, Dourados, MS, Brasil-gessi.ceccon@embrapa.br
}

Revista Brasileira de Milho e Sorgo, v.18, n.2, p. 206-220, 2019

\begin{abstract}
RESUMO - A densidade de plantas é uma das variáveis agronômicas com maior influência sobre a produtividade de grãos e, em sistemas consorciados, pode minimizar a interferência da braquiária sobre o milho. Objetivou-se avaliar o teor de nutrientes foliares e a produção de massa e grãos de milho safrinha, consorciado com Brachiaria brizantha cv. BRS Paiaguás, com populações de plantas, em espaçamento reduzido. A pesquisa foi conduzida na safrinha de 2016, em Dourados-MS, em delineamento experimental de blocos casualizados, com parcelas subdivididas, e quatro repetições. As parcelas foram constituídas pelos sistemas de cultivo de milho solteiro e consorciado e as subparcelas, pelas populações de plantas de milho $(45.000,52.000,65.000$ e 96.000 plantas ha-1). O consórcio milho-braquiária reduziu os teores foliares de $\mathrm{N}, \mathrm{P}, \mathrm{Ca}, \mathrm{S}$ e Cu do milho, mas incrementou a massa seca de palha na maior população. A massa seca por planta, o número e massa de grãos por espiga diminuíram com o aumento da população de milho, porém a massa seca total e a produtividade da cultura aumentaram, independentemente da presença da forrageira. As populações de plantas de milho têm maior influência sobre o seu crescimento e produtividade do que a presença da braquiária. Palavras-chave: Zea mays, Brachiaria brizantha, arranjo de plantas, competição interespecífica, competição intraespecífica.
\end{abstract}

\section{YIELD AND NUTRIENT CONTENT IN OFF-SEASON MAIZE POPULATION SINGLE AND INTERCROPPED WITH BRACHIARIA}

\begin{abstract}
In the management of plant arrangement, population density is one of the variables with higher effect on grain yield and can minimize the interference of the Brachiaria on corn in intercropping systems. The aim of this study was to evaluate the foliar nutrient content and production of mass and grains in the off-season maize intercropped with Brachiaria brizantha cv. BRS Paiaguás, with plant populations with reduced spacing. The study was conducted at off-season 2016 in Dourados-MS, in a randomized block design with split-plot and four replications. The plots were composed by the maize cropping systems (single and intercropped) and the split-plots by the maize populations (45,000, 52,000, 65,000 and 96,000 plants ha ${ }^{-1}$ ). The intercropping maize-Brachiaria reduced leaf contents of $\mathrm{N}, \mathrm{P}, \mathrm{Ca}, \mathrm{S}$, and $\mathrm{Cu}$ in corn, and increased the dry weight of straw in the highest population. Dry weight per plant, ear number and grain mass decreased with increasing corn population, but total dry matter and crop yield increased regardless the presence of forage. The plant populations showed greater effect on growth and yield of maize than the presence of Brachiaria.
\end{abstract} Keywords: Zea mays, Brachiaria brizantha, plant arrangement, interspecific competition, intraspecific competition. 
O consórcio de milho com Brachiaria ruziziensis se destaca como o principal sistema de produção de palha e grãos na safrinha (Ceccon, 2013), especialmente na região do Cerrado, onde a palha exerce importante função na manutenção da umidade, amenizando os efeitos da estiagem na entressafra, e na proteção do solo contra a erosão (Sá et al., 2010). Contudo, a interferência interespecífica pode provocar menor crescimento e desenvolvimento das espécies consorciadas e inviabilizar o sistema, como na competição por nutrientes (Costa et al., 2012).

$\mathrm{O}$ nitrogênio $(\mathrm{N})$ é o nutriente que as plantas de milho acumulam em maior quantidade, seguido do potássio $(\mathrm{K})$ e fósforo $(\mathrm{P})$. A maior parte do $\mathrm{N}$ e do $\mathrm{K}$ é acumulada antes do florescimento, quando o sistema radicular ainda é pouco desenvolvido (Duarte et al., 2003). Por isso, a elevada demanda por nutrientes nesta fase pode intensificar a competição em cultivos consorciados.

O conhecimento do comportamento das espécies em competição por fatores de produção tornase de grande importância para o êxito dos sistemas consorciados (Costa et al., 2012). Uma das maneiras de modificar a relação de competição, por água, luz e nutrientes em favor da cultura é por meio de práticas de manejo, como o arranjo espacial de plantas. A densidade de plantas é considerada uma das formas de manipulação do arranjo espacial com maior interferência sobre a produtividade do milho (Sangoi \& Silva, 2006).

Alguns trabalhos têm mostrado o efeito dos espaçamentos em sistemas consorciados (Borghi et al., 2008; Brambilla et al., 2009), mas informações sobre o efeito de populações de plantas de milho sobre a braquiária, em espaçamento reduzido, ainda são escassas e podem ser relevantes, quando deseja-se mi- nimizar o potencial competitivo da forrageira e obter elevadas produtividades de grãos. Avaliações do teor de nutrientes, da produção de massa seca e de grãos podem, portanto, auxiliar na escolha do melhor arranjo populacional de plantas em sistemas de cultivo, como no consórcio milho-braquiária.

O trabalho foi realizado com o objetivo de avaliar a produtividade de grãos, acúmulo de massa seca e de nutrientes em populações de milho safrinha, solteiro e consorciado com braquiária, em espaçamento reduzido $(0,45 \mathrm{~m})$.

\section{Material e Métodos}

O trabalho foi realizado na área experimental da Embrapa Agropecuária Oeste durante a safrinha de 2016, em sucessão à soja, numa área cultivada há dez anos sob sistema de plantio direto, em Dourados-MS $\left(22^{\circ} 16^{\prime} \mathrm{S}\right.$ e $54^{\circ} 49^{\prime} \mathrm{W}$, a $\left.408 \mathrm{~m}\right)$.

O clima da região é o Cwa de Köppen, e os dados climáticos do período experimental estão apresentados na Figura 1. Os dados de precipitação, temperatura média e água disponível no solo durante o período de condução do experimento (Figura 1) foram obtidos na Estação Meteorológica da Embrapa Agropecuária Oeste, disponíveis no portal Guia Clima.

O solo da área é classificado como Latossolo Vermelho Distroférrico, com textura muito argilosa (Santos et al., 2013). Os resultados da análise química do solo, obtidos da camada de 0-20 cm (Tabela 1), mostraram que os teores de cálcio $(\mathrm{Ca})$ e magnésio $(\mathrm{Mg})$ estavam dentro da faixa considerada adequada para a região do Cerrado. $\mathrm{O}$ teor de ferro $(\mathrm{Fe})$ foi considerado médio e os demais macro e micronutrientes apresentaram teores elevados (Sousa \& Lobato, 2004). 


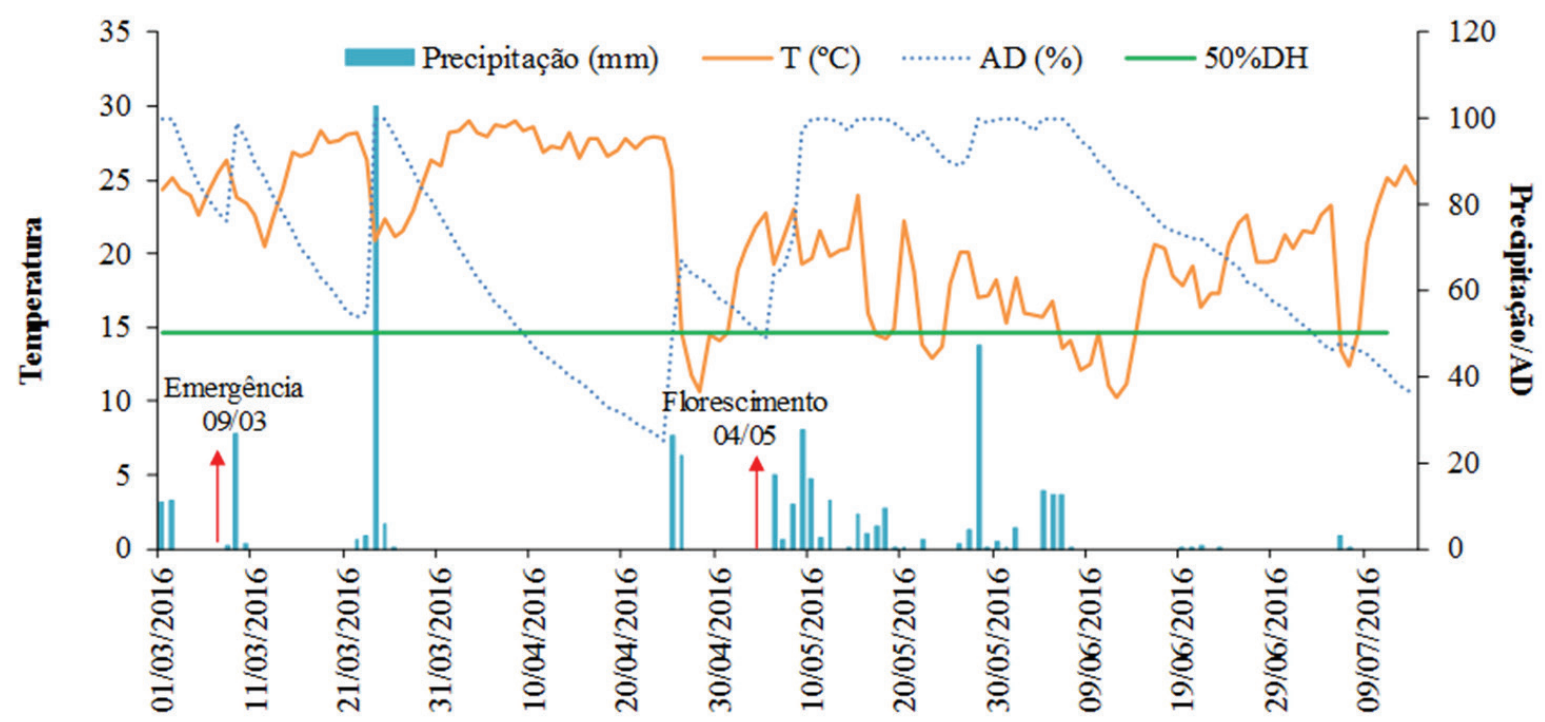

Figura 1. Precipitação, temperatura média (T), água disponível (AD) e limite de $50 \%$ de disponibilidade hídrica $(50 \% \mathrm{DH})$ durante a condução do experimento (março a julho de 2016), em Dourados-MS, 2018. Fonte: Guia Clima (2016)

Tabela 1. Caracterização química do solo da área experimental. Dourados-MS, 2018.

\begin{tabular}{|c|c|c|c|c|c|c|c|}
\hline pH Água ${ }^{1}$ & $\mathbf{A l}^{3+}$ & $\mathrm{Ca}^{2+}$ & $\mathrm{Mg}^{2+}$ & $\mathbf{H}^{+}+\mathbf{A l}^{3+}$ & $\mathbf{K}^{+}$ & SB & CTC (pH 7,0) \\
\hline $1: 2,5$ & \multicolumn{7}{|c|}{ 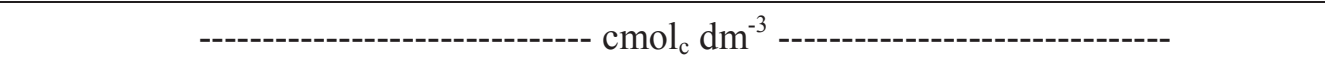 } \\
\hline 6,06 & 0,00 & 5,29 & 1,99 & 4,32 & 0,53 & 7,81 & 12,13 \\
\hline P $\left(\right.$ Mehlich $\left.^{-1}\right)$ & $\mathrm{Cu}^{2+}$ & $\mathrm{Fe}^{3+}$ & $\mathrm{Mn}^{2+}$ & $\mathrm{Zn}^{2+}$ & MO & C total & V \\
\hline \multicolumn{5}{|c|}{ 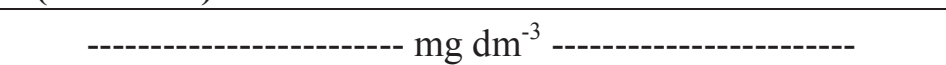 } & $\mathrm{g} \mathrm{kg}^{-1}$ & \multicolumn{2}{|c|}{----------- \% ------------ } \\
\hline 45,58 & 11,40 & 29,99 & 110,76 & 4,57 & 31,01 & 1,80 & 64,37 \\
\hline
\end{tabular}

${ }^{1} \mathrm{pH}$ : potencial hidrogeniônico; $\mathrm{Al}^{3+}$ : alumínio; $\mathrm{Ca}^{2+}$ : cálcio; $\mathrm{Mg}^{2+}$ : magnésio; $\mathrm{H}^{+}+\mathrm{Al}^{3+}$ : acidez potencial; $\mathrm{K}^{+}$: potássio; $\mathrm{SB}$ : soma de bases trocáveis; CTC: capacidade de troca catiônica efetiva; P: fósforo; Cu: cobre; Fe: ferro; Mn: manganês; Zn: zinco; MO: matéria orgânica; C: carbono; V: saturação por bases

O delineamento experimental foi em blocos ao acaso, em parcelas subdivididas, com quatro repetições. As parcelas foram constituídas pelos sistemas de cultivo de milho (solteiro e consorciado com braquiária) e as subparcelas, pelas populações de plantas de milho (45.000, 52.000, 65.000 e 96.000 plantas ha$\left.{ }^{1}\right)$. As unidades experimentais, independentemente do sistema de cultivo, foram compostas por sete linhas de milho com seis metros de comprimento e $0,45 \mathrm{~m}$ de espaçamento, sendo considerada área útil apenas as três linhas centrais.

Em 4 de março de 2016, foi realizada a semeadura do milho (DKB 390 PRO), a uma taxa de nove sementes $\mathrm{m}^{-1}$, e em seguida da Brachiaria brizantha $\mathrm{cv}$. BRS Paiaguás, com população de 20 plantas $\mathrm{m}^{-1}$ em espaçamento de 0,50 m entrelinhas. Aproximadamente dez dias após a emergência do milho (V3) foi realizado o desbaste das plantas para ajuste das populações. 
Na pré-emergência da cultura foi realizada a dessecação da área com Paraquat + Diuron $(0,4 \mathrm{~kg}$ $\left.\mathrm{ha}^{-1}+0,2 \mathrm{~kg} \mathrm{ha}^{-1}\right)$ e Atrazine $\left(1,5 \mathrm{~kg} \mathrm{ha}^{-1}\right)$. O controle de pragas iniciais foi realizado com imidacloprido + tiodicarbe $\left(35 \mathrm{~g} \mathrm{ha}^{-1}+125 \mathrm{~g} \mathrm{ha}^{-1}\right)$. Aos 10 DAE foi aplicado imidacloprido $+\beta$-ciflutrina $\left(75 \mathrm{~g} \mathrm{ha}^{-1}+9,37\right.$ $\mathrm{g} \mathrm{ha}^{-1}$ ) para o controle de Spodoptera frugiperda.

No pleno florescimento do milho $(\geq 50 \%$ das plantas em antese) foi realizada a coleta da folha oposta e abaixo da espiga, para avaliação da área foliar e composição química. A área foliar por planta $\left(\mathrm{AFP}-\mathrm{cm}^{2}\right.$ ) foi estimada pela equação: $0,75 \times \mathrm{C} \mathrm{x} \mathrm{L}$ $\mathrm{x}$ NF após avaliações do comprimento $(\mathrm{C}-\mathrm{cm})$ e da maior largura $(\mathrm{L}-\mathrm{cm})$ da folha e contagem do número de folhas (NF) fotossinteticamente ativas $(\geq 50 \%$ da área foliar verde). $O$ índice de área foliar (IAF) foi obtido pela relação entre a área foliar da planta e a área de solo ocupada por ela (AFP/área). Na análise química das folhas foram determinados os teores de macro ( $\mathrm{N}, \mathrm{P}, \mathrm{K}, \mathrm{Ca}, \mathrm{Mg}$ e $\mathrm{S}$ ) e micronutrientes ( $\mathrm{Zn}$, $\mathrm{Mn}, \mathrm{Fe}, \mathrm{Cu}, \mathrm{Na}$ e Bo), conforme metodologia descrita por Malavolta et al. (1997).

No estádio de maturação fisiológica do milho (127 DAE) foi realizada a coleta de oito amostras de plantas por parcela para avaliação da massa fresca total e da produtividade de grãos ( $\mathrm{PG}$ - $\left.\mathrm{kg} \mathrm{ha}^{-1}\right)$, corrigida para $13 \%$ de umidade. Em duas plantas representativas da amostra foram avaliados os caracteres morfológicos e componentes produtivos a seguir: altura de plantas de milho (APM - m), altura de inserção de espiga (AIE - m), diâmetro de colmo (DC - cm), massa seca por planta (MSPmilho) e massa seca total (MSTmilho - $\mathrm{kg} \mathrm{ha}^{-1}$ ), massa de cem grãos (M100 - g), número de grãos por espiga (NGE), massa de grãos por espiga (MGE - g).

A amostragem da braquiária foi realizada mediante corte das plantas rente ao solo em uma linha de $1 \mathrm{~m}$. O material coletado foi pesado para determinação da massa seca total da parte aérea (MSTB - kg $\left.\mathrm{ha}^{-1}\right)$ e, posteriormente, avaliado número de perfilhos (NP), altura (APB - m) e índice de perfilhos (IP).

A produção de massa seca de palha (MSTpalha - $\mathrm{kg} \mathrm{ha}^{-1}$ ) do sistema consorciado foi estimada pelo somatório das massas secas de milho e de braquiária.

Os dados foram submetidos à análise de variância pelo teste $\mathrm{F}(\mathrm{P} \leq 0,05)$, e quando significativos realizou-se a comparação de médias dos sistemas de cultivo pelo teste de Tukey $(\mathrm{P} \leq 0,05)$ e análise de regressão das populações de plantas no programa Sisvar. O grau de relação entre as variáveis do milho e a produtividade de grãos foi obtido pela análise de correlação de Pearson, e a significância do coeficiente avaliada pelo teste $\mathrm{t}(\mathrm{P} \leq 0,05)$, com auxílio do programa SAEG.

\section{Resultados e Discussão}

A análise de variância (Tabelas 2 e 3) indicou interação significativa entre população de plantas e sistema de cultivo para massa seca total de milho (MSTmilho) e de palha (MSTpalha). Houve efeito isolado do sistema de cultivo para teores de $\mathrm{N}, \mathrm{P}, \mathrm{Ca}$, $\mathrm{S}$ e $\mathrm{Cu}$, diâmetro de colmo (DCM) e índice de área foliar (IAF). A população de plantas influenciou significativamente as variáveis área foliar (AFP), índice de área foliar (IAF), número de perfilhos (NP) e massa seca total da braquiária (MSTbraq), massa seca por planta de milho (MSPmilho), número de grãos (NGE) e massa de grãos por espiga (MGE) e produtividade de grãos (PG).

No decorrer do desenvolvimento vegetativo do milho houve ocorrência de chuvas mal distribuídas, veranicos e elevadas temperaturas (entre 31 e $35^{\circ} \mathrm{C}$ ), resultando em níveis insatisfatórios de umidade do 
Tabela 2. Resumo da análise de variância para altura de plantas (APB), número (NP) e índice de perfilhos (IP) e massa seca total (MSTB) de braquiária em cultivo solteiro e consorciado, com populações de plantas de milho em espaçamentos reduzido, na safrinha 2016. Dourados-MS, 2018.

\begin{tabular}{cccccc}
\hline \multirow{2}{*}{ F.V. } & G.L. & \multicolumn{4}{c}{ Quadrados Médios } \\
\cline { 3 - 5 } & & APB & NP & IP & MSTB \\
\hline Bloco & 3 & $74,18^{\mathrm{ns}}$ & $6,75^{\mathrm{ns}}$ & $0,43^{\mathrm{ns}}$ & $139271,06^{*}$ \\
População (P) & 3 & $233,30^{*}$ & $210,41^{*}$ & $3,03^{\mathrm{ns}}$ & $303078,22^{* *}$ \\
Erro (a) & 9 & 58,25 & 10,25 & 1,39 & 25056,72 \\
\hline CVa (\%) & & 10,41 & 10,72 & 25,09 & 13,10 \\
\hline Média geral & & 73,29 & 29,87 & 4,71 & $1.208,18$ \\
\hline
\end{tabular}

**, ${ }^{*} \mathrm{e}^{\text {ns: }}$ : significativo a $1 \%(\mathrm{P} \leq 0,01), 5 \%(\mathrm{P} \leq 0,05)$ e não significativo pelo teste $\mathrm{F}$, respectivamente. G.L.: graus de liberdade. CVa: coeficientes de variação da parcela.

solo, que se estendeu até o pendoamento (VT) (Figura 1). A partir do florescimento (R1) houve grande ocorrência de chuvas, possibilitando manter a disponibilidade hídrica no solo elevada, minimizando os efeitos da estiagem ocorrida. Contudo, a precipitação total do período experimental (409 mm) não foi suficiente para suprir a quantidade de água normalmente consumida por uma lavoura de milho, $600 \mathrm{~mm}$ aproximadamente (Magalhães \& Durães, 2008), indicando a possibilidade de ter ocorrido déficit hídrico em algum momento do desenvolvimento da cultura.

Além da ocorrência de estiagem, houve registro de geadas no mês de junho. As condições climáticas desta safra resultaram em queda da produtividade média na região em torno de $38 \%$ em relação ao ano anterior (IBGE, 2016).

Os resultados da análise química foliar mostraram que a população de plantas não interferiu sobre o teor de nutrientes nas folhas de milho, contudo, os sistemas de cultivo afetaram os teores de $\mathrm{N}, \mathrm{P}, \mathrm{Ca}, \mathrm{S}$ e $\mathrm{Cu}$. Os demais nutrientes não apresentaram efeito significativo dos tratamentos e foram considerados adequados para a cultura do milho, exceto o boro (Coelho \& França, 1995).
O consórcio milho-braquiária apresentou menores teores de $\mathrm{N}, \mathrm{P}, \mathrm{Ca}, \mathrm{S}$ e $\mathrm{Cu}$ nas folhas em relação ao milho solteiro. Exceto o N, os demais nutrientes ainda permaneceram em concentrações adequadas para a cultura. $\mathrm{O}$ teor de $\mathrm{Ca}$, embora tenha sido menor no consórcio, foi superior ao limite máximo da faixa de suficiência nutricional adequada para o milho (Coelho \& França, 1995), refletindo em suprimento do solo satisfatório ao desenvolvimento de ambas as culturas (Tabela 4).

$\mathrm{O} \mathrm{N}$ está entre os nutrientes mais absorvidos pelo milho e pela braquiária e, em cultivo simultâneo, a grande exigência deste nutriente pode levar à competição e reduzir sua concentração a valores críticos, como também foi verificado por Fiorentin et al. (2012) e Costa et al. (2012). Quanto mais próximas, morfofisiologicamente são as espécies, mais similares são as exigências em relação aos fatores de crescimento, intensificando a competição (Brighenti \& Oliveira, 2011).

Em pesquisas realizadas por Foloni et al. (2008), a braquiária mostrou-se altamente eficiente na absorção de $\mathrm{P}$, mesmo oriundo de fonte pouco solúvel, o que se deve ao sistema radicular bastante 
Tabela 3. Resumo da análise de variância para teores foliares de nitrogênio $(\mathrm{N})$, fósforo $(\mathrm{P})$, potássio $(\mathrm{K})$, cálcio $(\mathrm{Ca})$, magnésio $(\mathrm{Mg})$, enxofre $(\mathrm{S})$, zinco $(\mathrm{Zn})$, manganês $(\mathrm{Mn})$, ferro $(\mathrm{Fe})$, cobre $(\mathrm{Cu})$, sódio $(\mathrm{Na})$ e boro (B), altura de plantas de milho (APM), altura de inserção da primeira espiga (AIE), diâmetro de colmo (DCM), área foliar por planta (AFP), índice de área foliar (IAF), massa seca por planta (MSPmilho), massa seca total (MSTmilho), massa seca total de palha (MSTpalha), massa de cem grãos (M100), número (NGE) e massa de grãos por espiga (MGE) e produtividade de grãos (PG) de milho em cultivo solteiro e consorciado, com populações de plantas em espaçamento reduzido, na safrinha 2016. Dourados-MS, 2018.

\begin{tabular}{|c|c|c|c|c|c|c|c|c|}
\hline \multirow{2}{*}{ F.V. } & & \multirow{2}{*}{ G.L. } & \multicolumn{6}{|c|}{ Quadrados Médios } \\
\hline & & & $\mathbf{N}$ & $\mathbf{P}$ & $\mathbf{K}$ & $\mathbf{C a}$ & Mg & $\mathbf{S}$ \\
\hline \multicolumn{2}{|l|}{ Bloco } & 3 & $0,015^{\mathrm{ns}}$ & $0,018^{\mathrm{ns}}$ & $1,63^{\mathrm{ns}}$ & $0,22^{\mathrm{ns}}$ & $0,009^{\mathrm{ns}}$ & $0,003^{*}$ \\
\hline \multicolumn{2}{|l|}{$\begin{array}{c}\text { Sistema } \\
\text { de Cultivo (SC) }\end{array}$} & 1 & $0,635^{* *}$ & $1,201^{* *}$ & $1,98^{\mathrm{ns}}$ & $2,30 *$ & $0,241^{\mathrm{ns}}$ & $0,259^{* *}$ \\
\hline \multicolumn{2}{|l|}{ Erro (a) } & 3 & 0,001 & 0,013 & 1,89 & 0,06 & 0,048 & 0,0003 \\
\hline \multicolumn{2}{|l|}{ População (P) } & 3 & $0,004^{\mathrm{ns}}$ & $0,002^{\mathrm{ns}}$ & $1,67^{\mathrm{ns}}$ & $0,15^{\mathrm{ns}}$ & $0,041^{\mathrm{ns}}$ & $0,0001^{\mathrm{ns}}$ \\
\hline \multicolumn{2}{|l|}{$\mathbf{S C} \times \mathbf{P}$} & 3 & $0,017^{\mathrm{ns}}$ & $0,023^{\mathrm{ns}}$ & $1,39^{\text {ns }}$ & $0,10^{\mathrm{ns}}$ & $0,04^{\mathrm{ns}}$ & $0,002^{\mathrm{ns}}$ \\
\hline \multicolumn{2}{|l|}{ Erro (b) } & 18 & 0,082 & 0,055 & 2,30 & 0,30 & 0,124 & 0,015 \\
\hline \multirow{2}{*}{\multicolumn{2}{|c|}{$\begin{array}{l}\text { CVa (\%) } \\
\text { CVb }(\%)\end{array}$}} & & 1,24 & 4,54 & 7,34 & 5,06 & 10,30 & 1,05 \\
\hline & & & 10,40 & 9,37 & 8,10 & 10,72 & 16,54 & 6,85 \\
\hline \multicolumn{2}{|c|}{ Média geral } & & 2,76 & 2,52 & 18,74 & 5,16 & 2,13 & 1,84 \\
\hline \multirow{2}{*}{\multicolumn{2}{|c|}{ F.V. }} & G.I & \multicolumn{6}{|c|}{ Quadrados Médios } \\
\hline & & G.1 & Zn & Mn & Fe & $\mathbf{C u}$ & $\mathbf{N a}$ & $\mathbf{B}$ \\
\hline \multicolumn{2}{|l|}{ Bloco } & 3 & $241,32^{\mathrm{ns}}$ & $65,32^{\mathrm{ns}}$ & $922,90^{\mathrm{ns}}$ & $0,12^{\mathrm{ns}}$ & $0,00007^{\mathrm{ns}}$ & $0,67^{\text {ns }}$ \\
\hline \multicolumn{2}{|l|}{$\begin{array}{c}\text { Sistema } \\
\text { de Cultivo (SC) }\end{array}$} & 1 & $373,25^{\text {ns }}$ & $149,68^{\mathrm{ns}}$ & $0,06^{\mathrm{ns}}$ & $23,12^{* *}$ & $0,0013^{\mathrm{ns}}$ & $0,20^{\mathrm{ns}}$ \\
\hline \multicolumn{2}{|l|}{ Erro (a) } & 3 & 225,14 & 68,50 & 1312,75 & 0,08 & 0,0005 & 0,21 \\
\hline \multicolumn{2}{|l|}{ População (P) } & 3 & $270,91^{\mathrm{ns}}$ & $5,34^{\text {ns }}$ & $1160,01^{\mathrm{ns}}$ & $0,04^{\mathrm{ns}}$ & $0,0001^{\mathrm{ns}}$ & $0,25^{\mathrm{ns}}$ \\
\hline \multicolumn{2}{|l|}{$\mathbf{S C} \times \mathbf{P}$} & 3 & $336,90^{\mathrm{ns}}$ & $60,58^{\mathrm{ns}}$ & $981,54^{\mathrm{ns}}$ & $0,27^{\text {ns }}$ & $0,0005^{\mathrm{ns}}$ & $3,38^{\text {ns }}$ \\
\hline \multicolumn{2}{|l|}{ Erro (b) } & 18 & 217,31 & 39,50 & 1559,09 & 0,95 & 7,07 & 1,56 \\
\hline \multirow{2}{*}{\multicolumn{2}{|c|}{$\begin{array}{l}\text { CVa }(\%) \\
\text { CVb }(\%)\end{array}$}} & & 70,88 & 18,12 & 23,86 & 3,02 & 7,05 & 6,10 \\
\hline & & & 69,64 & 13,76 & 26,00 & 10,16 & 7,05 & 16,44 \\
\hline \multicolumn{2}{|c|}{ Média geral } & & 21,16 & 45,68 & 151,86 & 9,6 & 0,31 & 7,60 \\
\hline \multirow{2}{*}{ F.V. } & G.L. & \multicolumn{7}{|c|}{ Quadrados Médios } \\
\hline & G.L. & & $\mathbf{M}$ & AIE & DCM & AFP & IAF & MSPmilho \\
\hline Bloco & 3 & & $12^{\mathrm{ns}}$ & $409,87^{\mathrm{ns}}$ & $15,58^{\mathrm{ns}}$ & $2948988,94^{\mathrm{ns}}$ & $1,36^{\mathrm{ns}}$ & $2592,54^{\mathrm{ns}}$ \\
\hline $\begin{array}{l}\text { Sistema de } \\
\text { Cultivo (SC) }\end{array}$ & 1 & &, $5^{\mathrm{ns}}$ & $24,5^{\mathrm{ns}}$ & $27,28^{*}$ & $6696885,03^{\mathrm{ns}}$ & $1,76^{*}$ & $1606,77^{\mathrm{ns}}$ \\
\hline Erro (a) & 3 & &, 04 & 228,91 & 2,35 & 861558,86 & 0,16 & 4357,64 \\
\hline População (P) & 3 & & $6^{\mathrm{ns}}$ & $59,04^{\mathrm{ns}}$ & $2,68^{\mathrm{ns}}$ & $3321873,11^{*}$ & $16,25^{* *}$ & $7214,78^{* *}$ \\
\hline $\mathbf{S C} \times \mathrm{P}$ & 3 & & $02^{\mathrm{ns}}$ & $210,75^{\mathrm{ns}}$ & $3,16^{\mathrm{ns}}$ & $1077491,03^{\mathrm{ns}}$ & $0,21^{\mathrm{ns}}$ & $1851,96^{\mathrm{ns}}$ \\
\hline Erro (b) & 18 & & 59 & 80,86 & 4,40 & 461604,43 & 0,16 & 636,15 \\
\hline CVa (\%) & & & 21 & 11,83 & 7,11 & 11,11 & 7,75 & 31,73 \\
\hline CVb (\%) & & & 43 & 7,03 & 9,73 & 8,13 & 7,72 & 12,12 \\
\hline Média geral & & & 5,5 & 127,94 & 21,58 & 8.356 & 5,31 & 208,027 \\
\hline F.V. & G. & & & & Quadrado & s Médios & & \\
\hline F.V. & G.L. & $\mathbf{M}$ & milho & MSTpalha & M100 & NGE & MGE & PG \\
\hline Bloco & 3 & 261 & $72,41^{\text {ns }}$ & $2161307,11^{\mathrm{ns}}$ & $7,94^{\mathrm{ns}}$ & $3579,58^{\text {ns }}$ & $508,23^{\mathrm{ns}}$ & $2012355,58^{\mathrm{ns}}$ \\
\hline $\begin{array}{c}\text { Sistema de } \\
\text { Cultivo (SC) }\end{array}$ & 1 & 54 & $0,12^{\mathrm{ns}}$ & $9258980,28^{\mathrm{ns}}$ & $0,33^{\mathrm{ns}}$ & $3003,12^{\mathrm{ns}}$ & $213,52^{\mathrm{ns}}$ & $359976,12^{\mathrm{ns}}$ \\
\hline Erro (a) & 3 & $43^{\circ}$ & 28,70 & 3790462,19 & 5,41 & 3336,37 & 170,02 & 683059,20 \\
\hline População (P) & 3 & 2062 & $04,08^{* *}$ & $25350445,19^{* * *}$ & $2,86^{\mathrm{ns}}$ & $17129,75^{* *}$ & $1477,19^{* *}$ & $9279301^{* *}$ \\
\hline $\mathbf{S C} \times \mathbf{P}$ & 3 & 477 & $32,20^{*}$ & $6043815,44^{*}$ & $1,42^{\mathrm{ns}}$ & $3386,20^{\mathrm{ns}}$ & $230,15^{\mathrm{ns}}$ & $669067,45^{\mathrm{ns}}$ \\
\hline Erro (b) & 18 & 13 & 77,31 & 1588572,12 & 3,04 & 1776,72 & 156,48 & 488025 \\
\hline CVa (\%) & & & 37 & 24,20 & 9,37 & 15,91 & 14,43 & 14,67 \\
\hline CVb (\%) & & & 54 & 15,67 & 7,03 & 11,61 & 13,84 & 12,40 \\
\hline Média geral & & & 76 & 8.044 & 24,82 & 363 & 90,377 & 5.633 \\
\hline
\end{tabular}

${ }^{* *},{ }^{*} \mathrm{e}^{\mathrm{ns}}$ : significativo a $1 \%(\mathrm{P} \leq 0,01), 5 \%(\mathrm{P} \leq 0,05)$ e não significativo pelo teste $\mathrm{F}$, respectivamente. G.L.: graus de liberdade. $\mathrm{CVa}, \mathrm{CVb}$ : coeficientes de variação da parcela, e subparcela, respectivamente. 
Tabela 4. Teores de nitrogênio $(\mathrm{N})$, fósforo $(\mathrm{P})$, cálcio $(\mathrm{Ca})$, enxofre $(\mathrm{S})$ e cobre $(\mathrm{Cu})$ em folhas de milho nos sistemas de cultivo de milho safrinha, em espaçamento reduzido. Dourados-MS, 2018

\begin{tabular}{cccccccc}
\hline Sistemas de cultivo & $\mathbf{N}$ & $\mathbf{P}$ & $\mathbf{C a}$ & $\mathbf{S}$ & $\begin{array}{c}\mathbf{C u} \\
\left(\mathrm{mg} \mathrm{kg}^{-1}\right)\end{array}$ \\
\hline Consórcio & $26,1 \mathrm{~b}^{*}$ & $2,33 \mathrm{~b}$ & $4,89 \mathrm{~b}$ & $1,75 \mathrm{~b}$ & $8,75 \mathrm{~b}$ \\
Solteiro & $28,9 \mathrm{a}$ & $2,72 \mathrm{a}$ & $5,43 \mathrm{a}$ & $1,93 \mathrm{a}$ & $10,45 \mathrm{a}$ \\
\hline CVa (\%) & 1,24 & 4,54 & 5,06 & 1,05 & 3,02 \\
\hline Média & 2,76 & 2,52 & 5,16 & 1,84 & 9,6 \\
\hline
\end{tabular}

"Médias seguidas por letras iguais na coluna não diferem entre si pelo teste de Tukey $(\mathrm{P} \leq 0,05)$.

ramificado e volumoso, que favorece o contato raizsolo e aumenta a absorção do P por difusão e interceptação radicular.

Por causa da elevada tolerância à deficiência hídrica e capacidade de absorção de nutrientes em camadas mais profundas do solo da $B$. brizantha (Barducci et al., 2009), a ocorrência de déficit hídrico na fase vegetativa do milho também pode ter prejudicado o milho consorciado, reduzindo o teor de nutrientes absorvidos por fluxo de massa, como N, Ca, S e $\mathrm{Cu}$, e por difusão, como $\mathrm{P}$.

Entre as variáveis morfológicas avaliadas no milho, a altura de plantas (APM) e de inserção de espigas (AIE) e a área foliar por planta (AFP) não foram afetadas pelos tratamentos, apresentando em média $2,06 \mathrm{~m}, 1,28 \mathrm{~m}$ e $8.356 \mathrm{~cm}^{2}$, respectivamente.

$\mathrm{O}$ efeito dos sistemas de cultivo foi significativo para diâmetro de colmo (DCM) e índice de área foliar (IAF), com menores valores no consórcio (Tabela 5), provavelmente em resposta à redução do teor de nutrientes, principalmente $\mathrm{N}$.

A competição interespecífica pode atrasar o desenvolvimento normal da cultura e resultar em plantas com colmos mais finos, por causa da sua função de armazenamento de fotoassimilados, resultando em menor ganho de matéria seca (Fiorentin et al., 2012).
O IAF também apresentou efeito da população de plantas, assim como a área foliar por planta (AFP). $\mathrm{O}$ aumento da densidade populacional de milho causou redução linear da AFP, mas incrementou o IAF (Figura 2a).

Os resultados obtidos corroboram as observações feitas por Brachtvogel et al. (2012), em pesquisa realizada com seis populações de milho, e Sangoi et al. (2013), em estudos de dois híbridos de milho (antigo e atual), que verificaram decréscimo linear da área foliar com aumento da densidade de plantas.

O IAF é determinado pela razão entre a área foliar de uma população de plantas e a área de solo ocupada por ela, portanto, espera-se maiores índices de área foliar sob populações de plantas mais elevadas, mesmo com a redução do tamanho da folha.

As folhas representam o principal órgão responsável pelo processo fotossintético. A redução da produtividade de grãos pode ocorrer pela redução do índice de área foliar e da eficiência com que a RFA interceptada é utilizada pela cultura (Bergamaschi \& Matzenauer, 2014), como pode ser observado na análise de correlação de Pearson entre o índice de área foliar e a produtividade de grãos, que apresentou efeito positivo e significativo (Figura $2 b$ ). 
Tabela 5. Diâmetro de colmo de milho (DCM) e índice de área foliar (IAF) nos sistemas de cultivo de milho safrinha, em espaçamento reduzido. Dourados-MS, 2018

\begin{tabular}{cccc}
\hline Sistemas de cultivo & DCM & \multicolumn{2}{c}{ IAF } \\
& $(\mathrm{mm})$ & - \\
\hline Consórcio & $20,66 \mathrm{~b}^{*}$ & 5,07 & $\mathrm{~b}$ \\
Solteiro & $22,51 \quad \mathrm{a}$ & $5,54 \quad \mathrm{a}$ \\
\hline CVa (\%) & 9,4 & 7,73 \\
\hline Média & 21,58 & 5,31 \\
\hline
\end{tabular}

${ }^{*}$ Médias seguidas por letras iguais na coluna não diferem entre si pelo teste de Tukey $(\mathrm{P} \leq 0,05)$.

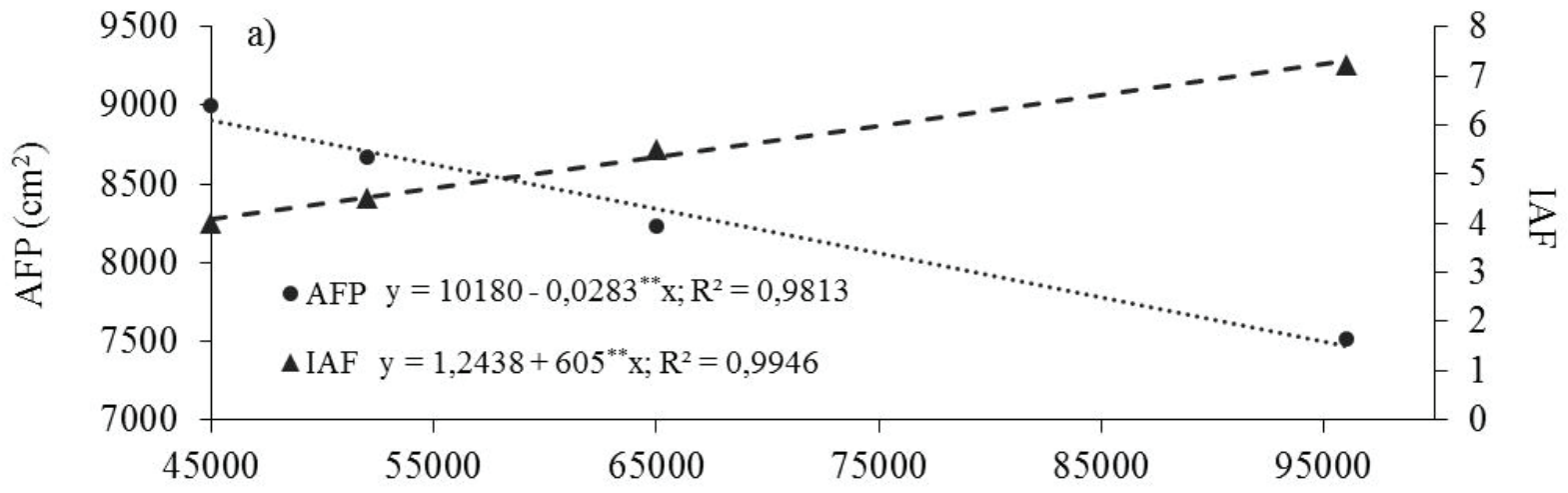

Populações de milho (plantas ha-1)

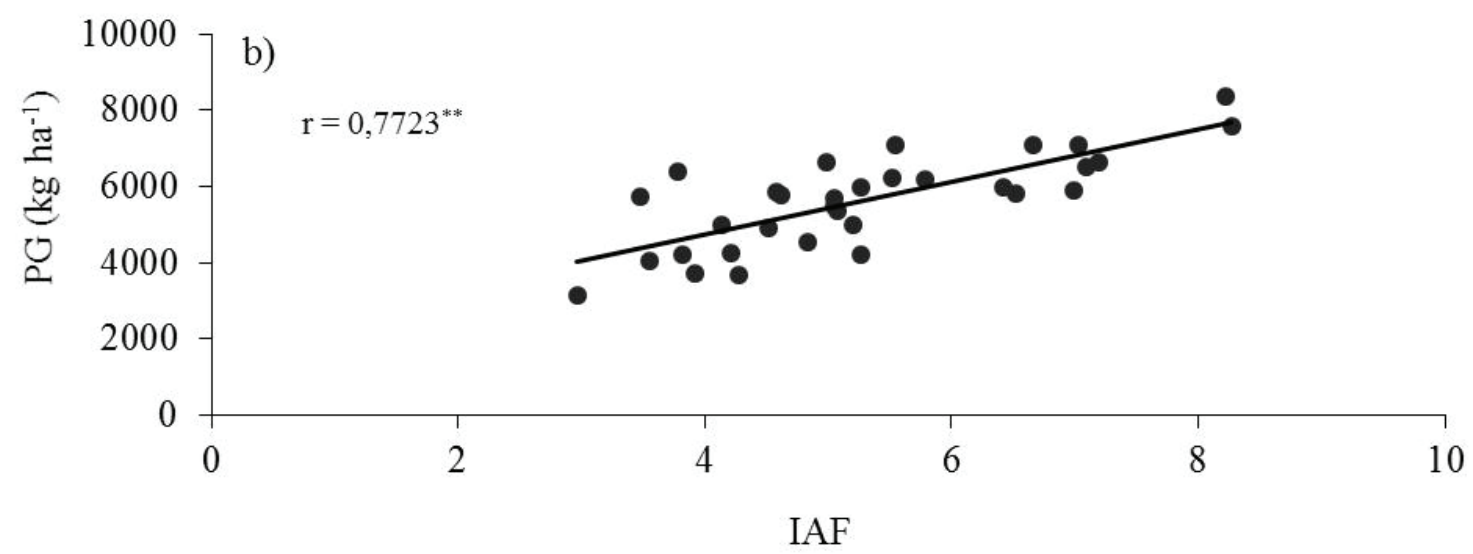

Figura 2. a) Área foliar por planta (AFP) e índice de área foliar (IAF) em populações de milho safrinha b) Correlação de Pearson entre produtividade de grãos (PG) e índice de área foliar (IAF), em função de populações de milho, em espaçamento reduzido. Dourados-MS, 2018 . $^{* *}(\mathrm{p} \leq 0,01)$ 
As populações de milho também influenciaram significativamente o número de perfilhos (NP) (Figura 3a) e a produção de massa seca total da braquiária (MST) (Figura 3b), que apresentaram resposta quadrática em relação às populações de milho.

O número de perfilhos reduziu até 67.759 plantas $\mathrm{ha}^{-1}$, apresentando em torno de 21,6 perfilhos $\mathrm{m}^{-1}$. Entretanto, a maior população de milho apresentou o maior perfilhamento da braquiária $(38,5$ perfilhos $\mathrm{m}^{-1}$ ), provavelmente porque houve maior índice de plantas de milho acamadas e quebradas, favorecendo a entrada de luz no dossel e a emissão de novos perfilhos. Segundo Martuscello et al. (2009), o aumento do nível de sombreamento reduz o número de perfilhos por planta, pois uma maior quantidade de fotoas- similados é alocada para o crescimento de perfilhos existentes em detrimento à emissão de novos.

A massa seca da braquiária decresceu até a população de 71.907 plantas ha ${ }^{-1}$, cuja produção de massa seca total atingiu um valor mínimo estimado em $835 \mathrm{~kg} \mathrm{ha}^{-1}$, o que representa uma redução de $45 \%$, aproximadamente. $\mathrm{O}$ acúmulo de massa da braquiária aumentou nas maiores populações de milho, mas manteve-se inferior em relação à menor população.

A produção de matéria seca de uma pastagem é diretamente proporcional ao número de perfilhos da forrageira na área (Martuscello et al., 2009). Consequentemente, ao afetar a produção de novos perfilhos, o sombreamento também pode reduzir a produção de matéria seca, por dificultar a translocação de fotoassi-
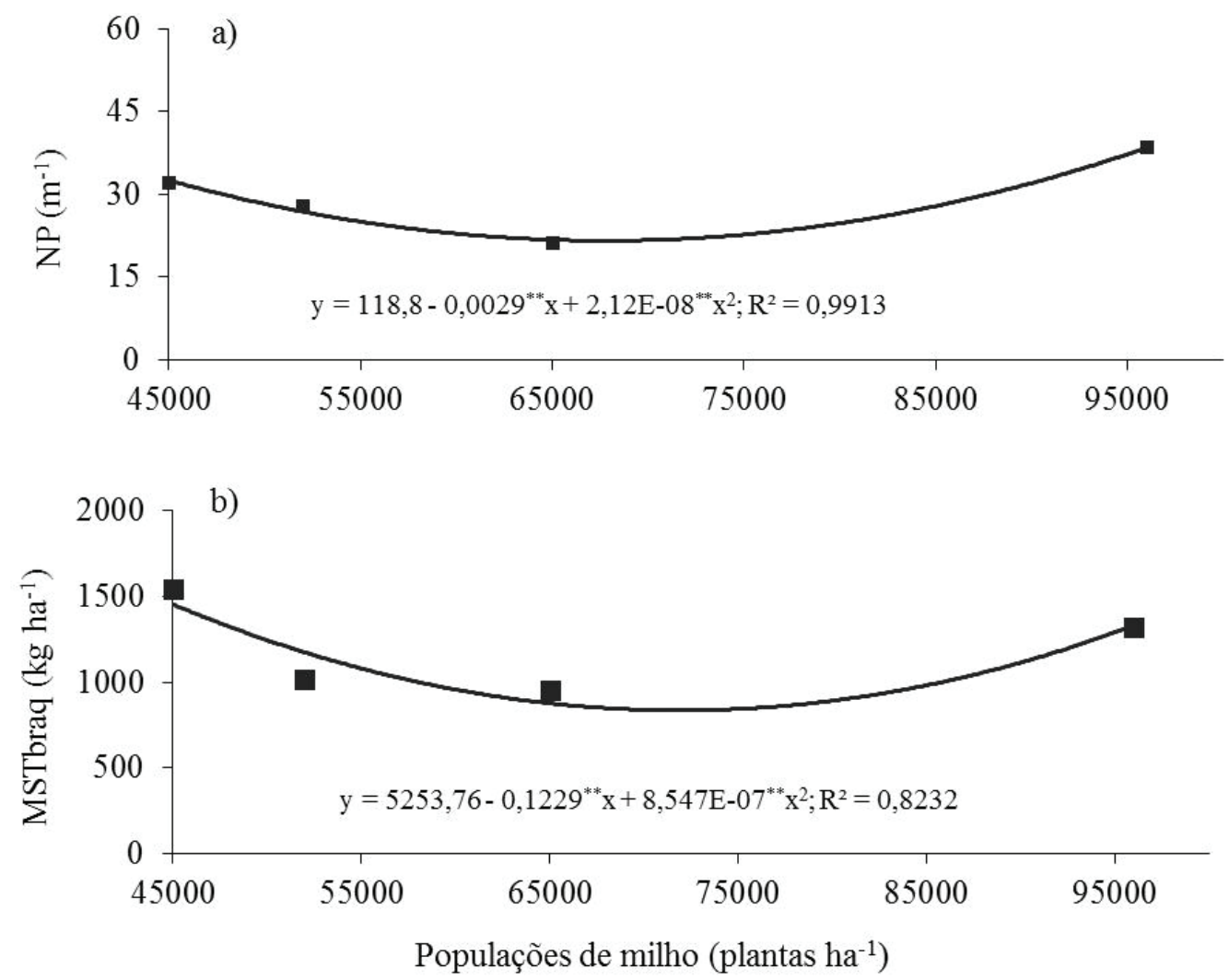

Figura 3. a) Número de perfilhos (NP) b) Massa seca total de braquiária (MSTbraq) em populações de milho safrinha, em espaçamento reduzido. Dourados-MS, 2018 . $^{* *}(\mathrm{p} \leq 0,01)$ 
milados, forçando a planta a antecipar o ciclo de desenvolvimento (Borghi et al., 2008).

A massa seca total de milho (MSTmilho) apresentou efeito significativo da interação entre populações e sistemas de cultivo (Figura 4a). A produção de massa seca por área no consórcio milho-braquiária teve melhor ajuste à equação linear, apresentando incrementos de 96,6 $\mathrm{g} \mathrm{ha}^{-1}$ na massa total para cada unidade de milho adicionada na área.

O cultivo de milho solteiro foi mais bem ajustado à equação polinomial e, dentre as populações estudadas, a maior produção de massa seca $(9.024 \mathrm{~kg}$ ha $^{-1}$ ) ocorreu em 78.688 mil plantas ha-1 ${ }^{-1}$, representan- do um incremento em torno de $3.040 \mathrm{~kg} \mathrm{ha}^{-1}$ de massa seca em relação à população de 45 mil plantas ha ${ }^{-1}$.

A massa seca por unidade de planta de milho (MSPmilho) apresentou comportamento linear decrescente com o aumento da população, provavelmente em decorrência do autossombreamento verificado nas maiores densidades de plantas, reduzindo 0,0012 $\mathrm{g}_{\text {planta }}{ }^{-1}$ com incremento de cada planta de milho (Figura 4b).

O aumento do sombreamento foliar em resposta ao aumento do índice de área foliar influencia negativamente a taxa de assimilação líquida (TAL), por causa da competição por luz e fotoassimilados
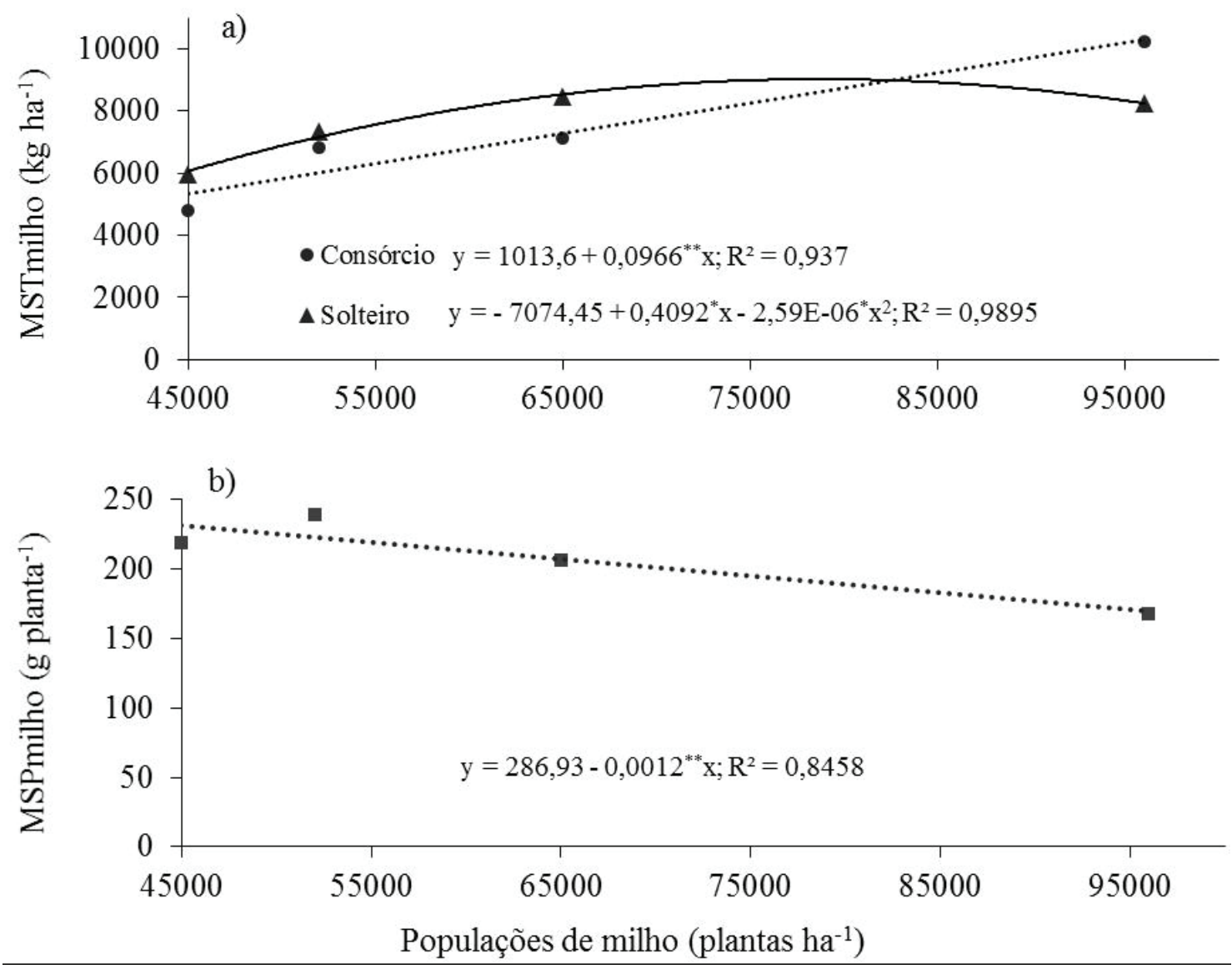

Figura 4. a) Massa seca total de milho (MSTmilho) em populações de plantas e sistemas de cultivo de milho safrinha b) Massa seca por planta de milho (MSPmilho) em populações de milho safrinha, em espaçamento reduzido. Dourados-MS, 2018. ${ }^{* *}(\mathrm{P} \leq 0,01) ;{ }^{*}(\mathrm{P} \leq 0,05)$ 
(Silva et al., 2016), por isso, maiores populações podem prejudicar o acúmulo de massa seca da planta. Brachtvogel et al. (2012) também observaram decréscimo da massa seca por planta com o aumento da população de milho, tanto no florescimento como na maturidade fisiológica. Entretanto, a produção de matéria seca por área aumentou à medida que se elevou a população de plantas, corroborando os resultados obtidos neste trabalho.

Os resultados demonstram que, apesar do aumento na densidade populacional de milho reduzir a produção de massa seca de uma unidade de planta, esta redução foi inferior ao incremento de massa na área total. A massa seca total de milho também apresentou correlação positiva e significativa com a produtividade de grãos $\left(0,8513^{* *}\right)$ (Figura 5a), demonstrando que a adoção de arranjos de plantas que favoreçam o crescimento da planta também possibilita aumentar seu potencial de produção.

A massa seca total de palha (MSTpalha) também apresentou efeito significativo da interação entre populações de plantas de milho e sistemas de cultivo (Figura 5b), apresentando melhor ajuste à equação linear, tanto no consórcio milho-braquiária como no cultivo solteiro

A braquiária possibilitou incrementar $110,9 \mathrm{~g}$ $\mathrm{ha}^{-1}$ de palha para cada unidade de milho no cultivo consorciado, enquanto no milho solteiro este incremento foi de apenas $36,6 \mathrm{~g} \mathrm{ha}^{-1}$. Na menor população, a produção de massa seca do milho solteiro foi maior que do consórcio. No entanto, a partir de 52 mil plantas ha ${ }^{-1}$, os menores valores de massa seca de palha de milho puderam ser compensados pela quantidade de palha produzida pela forrageira. Na maior população, a produção de palha do consórcio superou em 3.636 $\mathrm{kg} \mathrm{ha}^{-1}$ a do cultivo solteiro, representando um incremento de, aproximadamente, $30 \%$.
A quantidade de palha a ser adicionada anualmente à superfície do solo para manter a sustentabilidade do Sistema Plantio Direto (SPD), deve ser de 10 a $12 \mathrm{Mg} \mathrm{ha}^{-1}$ (Amado, 2000), e nesta pesquisa foi alcançada apenas no sistema consorciado, a partir da população estimada em 77.300 plantas ha-1.

Entre os componentes de produção do milho, apenas a massa de cem grãos (M100) não apresentou efeito dos tratamentos, com média de $24,82 \mathrm{~g}$. Os sistemas de cultivo também não influenciaram os componentes de produção avaliados no milho, demonstrando que apesar de afetar o teor de alguns nutrientes foliares e as características morfológicas, a competição entre plantas de braquiária e milho no sistema consorciado não foi capaz de comprometer a produtividade da cultura, corroborando Chioderoli et al. (2012).

A população de plantas de milho influenciou significativamente o número e a massa de grãos por espiga, com melhor ajuste ao modelo linear. Houve decréscimos de 19 grãos e 6 g por grão por espiga para cada aumento de 10 mil plantas de milho por hectare (Figura 6a).

O estresse causado pelo adensamento de plantas pode impactar o número de grãos produzidos por espiga, em decorrência do menor número de espiguetas fertilizadas, pela assincronia entre antese e espigamento, ou pelo aborto dos óvulos recém-fertilizados, por causa de limitações no suprimento de carbono e nitrogênio às espigas, após a fertilização (Sangoi et al., 2013).

A produtividade total de grãos apresentou efeito isolado da população de plantas, com melhor ajuste à equação quadrática (Figura 6b). Apesar de afetar a massa e o número de grãos por espiga, o aumento do número de plantas de milho possibilitou elevar a produtividade, atingindo $6.900 \mathrm{~kg} \mathrm{ha}^{-1}$ na população de 



Figura 5. a) Correlação de Pearson entre produtividade de grãos e massa seca total de milho (MSTmilho), em função de populações de milho b) Massa seca total de palha (MSTpalha) em populações de plantas e sistemas de cultivo de milho safrinha, em espaçamento reduzido. Dourados-MS, 2018. ${ }^{* *}(\mathrm{P} \leq 0,01) ;{ }^{*}(\mathrm{P} \leq 0,05)$

93.352 plantas ha ${ }^{-1}$, o que representa uma diferença de $37 \%$ em relação a menor população.

O aumento da produtividade de grãos pode ser atribuído ao incremento do número de plantas e, consequentemente, do número de espigas colhidas por área, compensando a redução do número e da massa de grãos por espiga. A produtividade obtida neste trabalho, independentemente da população de plantas, foi em média $40 \%$ superior à alcançada no Estado de Mato Grosso do Sul na mesma safra (IBGE, 2016). Segundo levantamento realizado em 2015, a maioria das lavouras de milho safrinha do estado tem sido cultivada em populações entre 40 a 60 mil plantas ha-1 (Neto Neto \& Ceccon, 2015), indicando que a adoção de maior número de plantas por hectare nesta região pode elevar a produtividade de milho safrinha, mesmo no consórcio com a braquiária. 



Figura 6. a) Número de grãos por espiga (NGE) e massa de grãos por espiga (MGE) b) Produtividade de grãos (PG) em populações de milho safrinha, em espaçamento reduzido. Dourados-MS, 2018. * $(\mathrm{P} \leq 0,05)$

\section{Conclusões}

O consórcio com a braquiária reduz os teores foliares de $\mathrm{P}, \mathrm{Ca}, \mathrm{S}$ e $\mathrm{Cu}$ do milho e, principalmente, de N. Porém, não compromete a produção de massa seca total, os componentes de produção e a produtividade da cultura.

O aumento da densidade populacional do milho reduz a massa seca por planta, o número e a massa de grãos por espiga, mas incrementa a produção de massa seca do milho, de palha e grãos por área, independentemente do sistema de cultivo.

As populações de plantas de milho têm maior influência sobre o seu crescimento e produtividade do que a presença da braquiária.

\section{Referências}

AMADO, T. J. Manejo da palha, dinâmica da matéria orgânica e ciclagem de nutrientes em plantio direto. In: ENCONTRO NACIONAL DE PLANTIO DIRETO NA PALHA, 7., 2000, Foz do Iguaçu, PR. Resumos... Foz do Iguaçu: FEBRAPDP, 2000. p. 105-111.

BARDUCCI, R. S.; COSTA, C.; CRUSCIOL, C. A. C.; BORGHI, E.; PUTAROV, T. C.; SARTI, L. M. N. Produção de Brachiaria brizantha e Panicum maximum com milho e adubação nitrogenada. Archivos de Zootecnia, Córdoba, v. 58, n. 222, p. 211-222, 2009.

BERGamasCHI, H.; MATZENAUER, R. O Milho e o clima. Porto Alegre: Emater-RS: Ascar, 2014. 84 p. 
BORGHI, E.; COSTA, N. V.; CRUSCIOL, C. A. C.; MATEUS, G. P. Influência da distribuição espacial do milho e da Brachiaria brizantha consorciados sobre a população de plantas daninhas em sistema plantio direto na palha. Planta Daninha, Viçosa, MG, v. 26, n. 3, p. 559568, 2008. DOI: 10.1590/S0100-83582008000300011.

BRACHTVOGEL, E. L.; PEREIRA, F. R. da S.; CRUZ, S. C. S.; ABREU, M. L. de; BICUDO, S. J. População, arranjo de plantas uniforme e a competição intraespecífica em milho. Revista Trópica - Ciências Agrárias e Biológicas, Chapadinha, v. 6, n. 1, p. 75-83, 2012.

BRAMBILlA, J. A.; LANGE, A.; BUCHELT, A. C.; MASSAROTO, J. A. Produtividade de milho safrinha no sistema de integração lavoura-pecuária, na região de Sorriso, Mato Grosso. Revista Brasileira de Milho e Sorgo, Sete Lagoas, v. 8, n. 3, p. 263-274, 2009. DOI: 10.18512/1980-6477/rbms.v8n3p263-274.

BRIGHENTI, A. M.; OLIVEIRA, M. F. Biologia de plantas daninhas. In: OLIVEIRA JÚNIOR, R. S.; CONSTANTIN, J.; INOUE, M. H. Biologia e manejo de plantas daninhas. Curitiba: Omnipax, 2011. p. 1-36.

CECCON, G. (Ed.). Consórcio milho-braquiária. Brasília, DF: Embrapa, 2013. 175 p.

CHIODEROLI, C. A.; MELLO, L. M. M. de; HOLANDA, H. V. de; FURLANI, C. E. A.; GRIGOLLI, P. J.; SILVA, J. O. da R.; CESARIN, A. L. Consórcio de Urochloas com milho em sistema plantio direto. Ciência Rural, Santa Maria, v. 42, n. 10, p. 1804-1810, 2012.

DOI: $10.1590 / \mathrm{S} 0103-84782012005000073$.

COELHO, A. M.; FRANÇA, G. E. Seja doutor do seu milho: nutrição e adubação. 2. ed. Piracicaba: Potafós, 1995. 9 p. (Arquivo do Agrônomo, 2).

COSTA, N. R.; ANDREOTTI, M; GAMEIRO, R. de A.; PARIZ, C. M.; BUZETTI, S.; LOPES, K. S. M. Adubação nitrogenada no consórcio de milho com duas espécies de braquiária em sistema plantio direto. Pesquisa Agropecuária Brasileira, Brasília, DF, v. 47, n. 8, p. 1038 1047, 2012. DOI: 10.1590/S0100-204X2012000800003.
DUARTE, A. P.; KIEHL, J. C.; CAMARGO, M. A. F.; RECO, P. C. Acúmulo de matéria seca e nutrientes em cultivares de milho originárias de clima tropical e introduzidas de clima temperado. Revista Brasileira de Milho e Sorgo, Sete Lagoas, v. 2, n. 3, p. 1-19, 2003. DOI: 10.18512/1980-6477/rbms.v2n3p1-20.

FIORENTIN, C. F.; LEMOS, L. B.; FORNASIERI FILHO, D.; JARDIM, C. A. Influência da consorciação com Brachiaria ruziziensis e do nitrogênio residual na cultura do milho. Revista de Ciências Agrárias, Lisboa, v. 35, n. 1, p. 184-192, 2012.

FOLONI, J. S. S.; TIRITAN, C. S.; CALONEGO, J. C.; ALVES JÚNIOR, J. Aplicação de fosfato natural e reciclagem de fósforo por milheto, braquiária, milho e soja. Revista Brasileira de Ciências do Solo, Viçosa, MG, v. 32, n. 3, p. 1147-1155, 2008.

DOI: $10.1590 / \mathrm{S} 0100-06832008000300023$.

GUIA CLIMA. Dourados: Embrapa Agropecuária Oeste, 2016. Disponível em: <http://clima.cpao.embrapa.br/>. Acesso em: 13 ago. 2016.

IBGE. Levantamento Sistemático da produção Agrícola. Rio de Janeiro, v. 12, n. 12, p. 1-82, 2016.

NETO NETO, A. L.; CECCON, G. Produção de milho safrinha em Mato Grosso do Sul. In: SEMINÁRIO NACIONAL DE MILHO SAFRINHA, 13., 2015, Maringá. Anais... Maringá: Universidade Estadual de Maringá, 2015. p. 578-591.

MAGAlHÃES, P. C.; DURÃES, F. O. M. Fisiologia da produção. In: CRUZ, J. C.; KARAM, D.; MONTEIRO, M. A. R.; MAGALHÃES, P. C. A cultura do milho. Sete Lagoas: Embrapa Milho e Sorgo, 2008. p. 63-87.

MALAVOLTA, E.; VITTI, G. C.; OLIVEIRA, S. A. Avaliação do estado nutricional das plantas: princípios e aplicações. 2. ed. Piracicaba: Potafós, 1997. 319 p.

MARTUSCELLO, J. A.; JANK, L.; NETO, M. M. G.; LAURA, V. A.; CUNHA, D. de N. F. V. da. Produção de gramíneas do gênero Brachiaria sob níveis de 
sombreamento. Revista Brasileira de Zootecnia, Viçosa, v. 38, n.7, p. 1183-1190, 2009.

DOI: $10.1590 / \mathrm{S} 1516-35982009000700004$.

SÁ, J. C. M.; FERREIRA, A. O.; BRIEDIS, C.; VIEIRA, A. M.; FIGUEIREDO, A. G. Crescimento radicular, extração de nutrientes e produção de grãos de genótipos de milho em diferentes quantidades de palha de aveia-preta em plantio direto. Revista Brasileira de Ciência do Solo, Viçosa, MG, v. 34, n. 4, p. 1207-1216, 2010.

DOI: $10.1590 / \mathrm{S} 0100-06832010000400020$.

SANGOI, L.; SILVA, P. R. F. da. Densidade e arranjo populacional em milho. 2006. Artigo em hypertexto. Disponível em: <http://www.infobibos.com/ Artigos/2006_2/Densidade/Index.htm>. Acesso em: 20 jan. 2019.

SANGOI, L.; ZANIN, C. G.; SCHMITT, A.; VIEIRA, J. Senescência foliar e resposta de híbridos de milho liberados comercialmente para cultivo em diferentes épocas ao adensamento. Revista Brasileira de Milho e Sorgo, Sete Lagoas, v. 12, n. 1, p. 21-32, 2013.

DOI: 10.18512/1980-6477/rbms.v12n1p21-32.

SANTOS, H. G. dos; JACOMINE, P. K. T.; ANJOS, L. H. C. dos; OLIVEIRA, V. A. de; LUMBRERAS, J. F.; COELHO, M. R.; ALMEIDA, J. A. de; CUNHA, T. J. F.; OLIVEIRA, J. B. de. Sistema Brasileiro de Classificação de Solos. 3. ed. Rio de Janeiro: Embrapa Solos, 2013.353 p.

SILVA, M. A.; FERREIRA, W. M.; ANDRADE, V.; COSTA, J. Influência das condições microclimáticas no crescimento do milho BR 106, cultivado sob sementeira direta. Revista de Ciências Agrárias, Lisboa, v. 39, n. 3, p. 383-394, 2016.

SOUSA, D. G. M. de; LOBATO, E. Correção da acidez do solo. In: SOUSA, D. G. M. de; LOBATO, E. (Ed.). Cerrado: correção do solo e adubação. 2. ed. Brasília, DF: Embrapa Informação Tecnológica; Planaltina: Embrapa Cerrados, 2004. p. 8196. 